\title{
A Case of Quadriplegia after Parotidectomy in a Patient with Asymptomatic Cervical Spondylosis
}

\author{
Min Jun Shin ${ }^{1}$, Hyun Gi Sohn ${ }^{1}$ Jung On Lee ${ }^{2}$, and Yong Jin Song ${ }^{1}$ \\ ${ }^{1}$ Department of Otorhinolaryngology, Gangneung Asan Hospital, University of Ulsan College of Medicine, Gangneung; and \\ ${ }^{2}$ Department of Otorhinolaryngology-Head and Neck Surgery, Ulsan University Hospital, University of Ulsan College of Medicine, \\ Ulsan, Korea
}

\section{무증상 경추 척추증 환자에서 이하선 절제술 후 발생한 사지마비 1예}

신민준 ${ }^{1} \cdot$ 손현기 $^{1} \cdot$ 이정온 ${ }^{2} \cdot$ 송용진 ${ }^{1}$

울산대학교 의과대학 강릉아산병원 이비인후과학교실, ${ }^{1}$ 울산대학교 의과대학 울산대학교병원 이비인후과학교실 ${ }^{2}$

\author{
Received June 14, 2018 \\ Revised August 30, 2018 \\ Accepted September 18, 2018 \\ Address for correspondence \\ Yong Jin Song, MD, PhD \\ Department of Otorhinolaryngology, \\ Gangneung Asan Hospital, \\ University of Ulsan \\ College of Medicine, \\ 38 Bangdong-gil, Sacheon-myeon, \\ Gangneung 25440, Korea \\ Tel $+82-33-610-3309$ \\ Fax $+82-33-642-3189$ \\ E-mail yjsong.yjs@gmail.com
}

Cervical spondylosis is a common degenerative disease of the cervical spine affecting the cervical vertebral bodies and intervertebral discs. During parotidectomy, the patient is placed in a supine position with the neck extended and head rotated to the contralateral side. This position could exacerbate pre-existing cervical spondylosis and cause cervical myelopathy. We present a case of postoperative quadriplegia secondary to cervical myelopathy after parotidectomy. A 68-year-old man without symptoms of cervical spondylosis underwent partial parotidectomy for a right parotid mass and subsequently developed quadriplegia 8 hours postoperatively. Magnetic resonance imaging revealed severe cervical myelopathy. Emergency laminoplasty was performed, and steroid therapy was initiated. He showed near-complete recovery six months later. Korean J Otorhinolaryngol-Head Neck Surg 2019;62(7):413-5

Key Words Cervical myelopathy · Cervical spondylosis · Head and neck surgery · Parotidectomy $\cdot$ Quadriplegia.

\section{서 론}

이하선 절제술(parotidectomy)은 두경부외과 영역에서 흔 히 시행되는 수술이다. 이하선 절제술 후 발생할 수 있는 대표 적인 합병증으로는 얼굴 신경 마비, Frey씨 증후군, 피판 괴 사, 재발 등이 있다. 이하선 절제술은 대개 앙와위 자세에서 술측의 반대편으로 머리를 회전시키고 목을 신전시킨 자세로 시행된다. 이 자세는 잠재적으로 기존의 경추 척추증(cervical spondylosis)을 악화시킬 수 있고 경추 척수병증(cervical myelopathy)을 초래할 수 있다. ${ }^{1-3)}$ 이하선 절제술 등 두경부 외과 수술 후 발생한 사지마비는 아직 국내에서 보고된 바가

This is an Open Access article distributed under the terms of the Creative Commons Attribution Non-Commercial License (https://creativecommons.org/licenses/by-nc/4.0) which permits unrestricted non-commercial use, distribution, and reproduction in any medium, provided the original work is properly cited.
없었다. 저자들은 경추 척추증을 진단받지 않은 환자에서 이 하선 절제술 후 경추 척수병증으로 인한 사지마비 증례를 경 험하였기에 문헌 고찰과 함께 보고하고자 한다.

본 연구는 강릉아산병원 기관생명윤리위원회(Institutional Review Board)의 승인을 받았다.

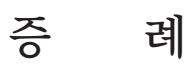

68세 남자가 5년 전부터 자각하고 있던 우측 이하선부위 종괴가 내원 3일 전부터 급격하게 크기가 증대되어 외래에 내 원하였다. 신체검사에서 오른쪽 이하선 부위에 압통, 열감이 동반된 $10 \mathrm{~cm}$ 크기의 종괴가 관찰되었다. 경부 컴퓨터단층촬 영을 시행하였으며, 우측 이하선 천엽부위 주변에 조영증강을 보이는 $3.5 \mathrm{~cm}$ 의 종물이 관찰되었으며, 주변 피하지방층으로 
염증이 파급되어 있는 소견이었다(Fig. 1). 술 전 사지의 근력 은 정상이었고 신경학적 증상은 호소하지 않았다. 우측 천엽 절제술(right partial superficial parotidectomy)을 시행하였 고, 병리조직학적으로 와르틴 종양(warthin tumor)으로 진단 되었다. 총 수술 시간은 4시간가량 소요되었다. 수술 직후 경 미한 목 통증을 호소하였고, 환자는 수술 후 8시간 만에 사지

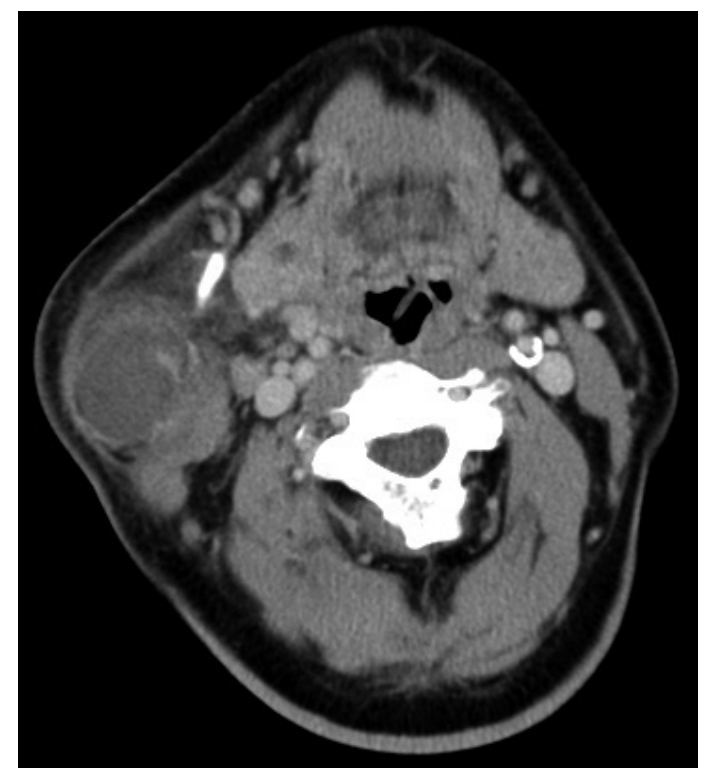

Fig. 1. An axial neck CT is showing rim enhancing lesion in right parotid gland superficial lobe lower portion and infiltration and thickening of the subcutaneous area and platysma muscle.

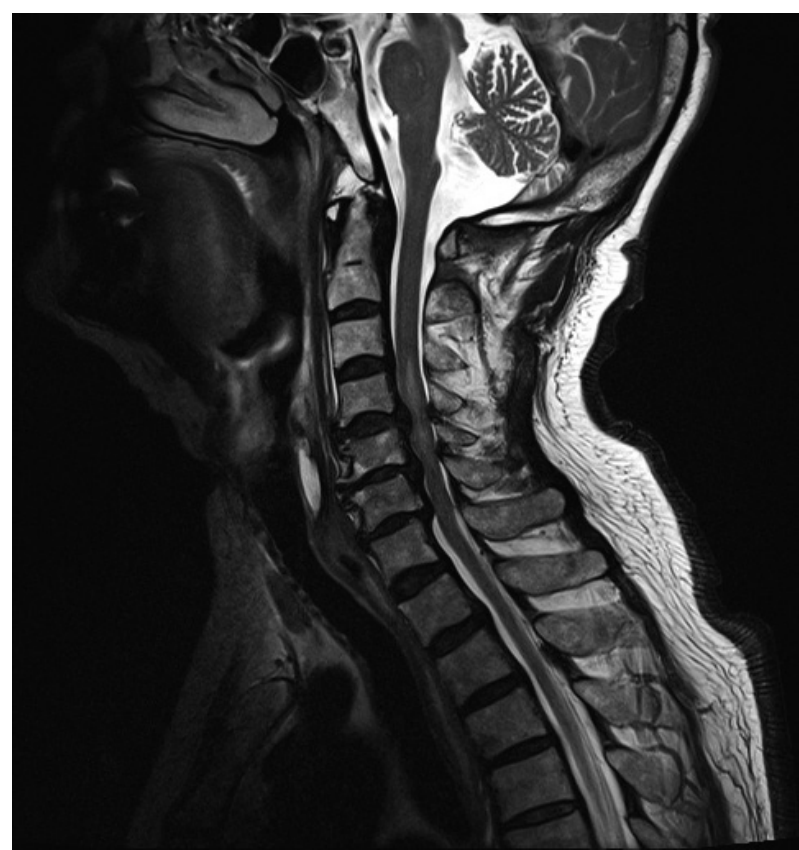

Fig. 2. T2-weighted sagittal MRI showing prominent high signal intensity edematous cord lesion from C3-4 to C5-6 associated with severe degree central spinal stenosis from C4-5 to C6-7 and underlying severe central spinal stenosis.
마비를 처음으로 보고하였다. 근력 평가 결과 양측 상지 $1 / 5$, 양측 하지 $1 / 5$ 의 현저한 근력 저하가 관찰되었다. 그러나 의식 변화, 감각 장애 등의 다른 신경학적 증상은 관찰되지 않았다.

즉각적으로 신경외과 협진을 의뢰하여 경추 자기공명영상 을 시행하였으며 T2 강조 영상에서 제4-5 경추간부터 제6-7 경추간에 이르는 심한 척추 협착(spinal stenosis)을 동반한 압박성 척수병증(compressive myelopathy)이 관찰되었다 (Fig. 2). 증상 호소 10시간 후 제4-5-6 경추의 편측 후궁을 열어 신경관을 확장시키는 좌측 개방문 추궁 성형술(left open door laminoplasty)을 시행하였고, 메틸프레드니솔론(methylprednisolone) $125 \mathrm{mg}$ 정맥 내 일시주사 후 매 6시간마다 $60 \mathrm{mg}$ 정맥 내 주사로 48시간 동안 스테로이드 치료(steroid therapy)를 시행하였다. 근력 회복은 양호하여 수술 3일 후 모 든 사지의 근력은 $4 / 5$ 까지 회복되었다. 추궁 성형술 시행 100 일 후 환자는 퇴원하였고, 약 2년 1개월이 지난 현재 환자는 경미한 고유수용성 감각 저하만을 보이며 수술 전 근력에 근 접하게 회복되어 지역사회 보행이 가능한 상태이다.

\section{고 찰}

중증의 경추 척수병증은 이하선 절제술이나 기타 두경부외 과 수술에서 매우 드문 합병증이다. 비척수수술인 두경부 수술 후 척수 손상은 이전에 갑상선 수술에서 보고된 바가 있었다. ${ }^{4)}$ 경추 척수병증의 병태생리는 아직 불분명하나 척수허혈, 경막외

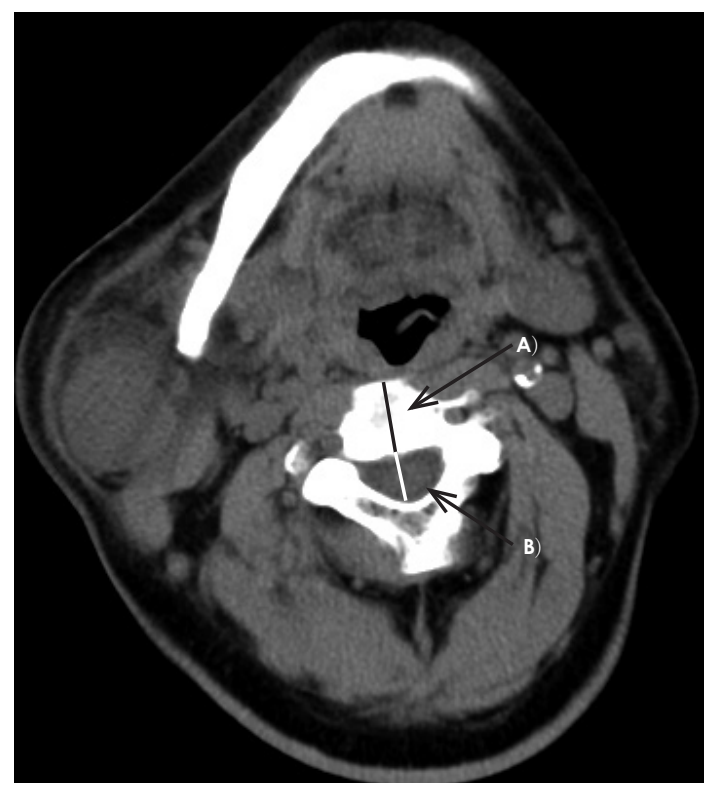

Fig. 3. Pre-operative radiologic evaluation on axial image of CT. Spinal canal diameter was measured at $\mathrm{C} 2-3$ intervertebral disk level. The spinal canal diameter to intervertebral disk diameter and Torg-pavlov ratio $(B / A \fallingdotseq 0.55)$ was calculated. $A$ : intervertebral disc (20.46 mm). B: spinal canal (11.23 mm). 
혈종, 직접적인 압박 또는 견인 등을 원인으로 추정하고 있다.

경추 척수병증은 경추의 노화에 의해 발생하는 진행성 병변 중 가장 흔하다. 이 질환은 골증식성골극(osteophytic spur) 의 발생이나, 척추사이원반(intervertebral disc)의 붕괴 및 돌 출, 그리고 황색 인대(ligamentum flavum)의 비대로 척추관 이 좁아지는 것이 특징이다.

증상이 없는 60 세 이상의 인구의 약 $85 \%$ 에서 다양한 정도 의 디스크 변성이 관찰된다. ${ }^{5)}$ 두경부외과 수술에서 자주 시행 되는 목의 신전은 기존의 무증상 경추 척추증을 신체적 기능 저하가 동반된 척추증으로 진행시킬 수 있다. 목 신전은 황색 인대의 굴곡과 척수 후방 종축 방향 혈관의 굴곡을 야기하 여 척수를 등 쪽에서 압박할 수 있다. ${ }^{6)}$ Brieg 등ㄱㄱㄱㅘ Taylor ${ }^{8}$ 는 골증식성 골극이 있을 때 과신전에 의해 척수의 심한 압박 이 발생할 수 있다고 보고하였다. 반면에 측면 굽힘 및 축 회 전은 신전에 비하여 척수에 적은 영향을 미친다. ${ }^{6}$ 또한 척추 관 협착은 굴곡시 보다 신전시에 두 배 증가하는 것이 관찰되 었다.9) 이러한 기전으로, 목을 신전시킨 자세로 장시간 시행되 는 수술은 경추 척수병증 증상을 유발할 수 있다.

수술 후 척수 손상 가능성을 두경부외과 수술 전 통상적으 로 시행하는 컴퓨터단층촬영이나 자기공명영상을 통하여 예 측할 수 있다. ${ }^{10)}$ 척추관 전후경(anteroposterior diameter of spinal canal)이 비교적 넓은 제2-3 경추간 척수사이원반 높 이에서 척추관 전후경과 척추사이원반의 전후경 비(TorgPavlov ratio)가 0.59 미만인 환자, 척추관 전후경이 $8 \mathrm{~mm}$ 미 만인 자, 신체검사상 경부를 편측으로 굽힌 후 머리 위쪽에서 압력을 가하는 스펄링 검사 양성 환자는 술 전 경추에 대한 평 가가 필요하다(Fig. 3). ${ }^{11-13)}$

본 증례의 환자와 같은 급성 척수 손상(acute spinal cord injury)으로 인한 불완전 사지마비(incomplete quadriplegia) 로 재활 치료를 받은 환자 중 $21 \%$ 의 환자가 6 개월 후 보행 능 력을 획득하지 못했다는 보고가 있다. ${ }^{14)}$ 또한 척수 손상 환자 는 장기적으로 폐렴 등의 호흡기계 질환과 자율신경 반사부 전(autonomic dysreflexia) 등의 심혈관계 질환을 비롯하여 방 광 기능부전(bladder dysfunction), 근육 경직(spasticity), 통 증 증후군(pain syndrome)이나 압박궤양(pressure ulcer)과 같은 다양한 만성적 합병증이 병발할 수 있다. ${ }^{15)}$

그러므로 수술 후 발생하는 사지마비는 조기 발견과 즉각 적인 중재가 매우 중요하다. 급성 척수 손상에서 스테로이드 치료와 수술적 중재 시기에 대하여 다소 논란이 있지만 척수 손상 발생 후 가능하면 8시간 이내에 스테로이드 요법을 시작 하고 24 시간 이내에 수술적 중재를 시행하는 것이 좋다. ${ }^{16,17)}$ 본 증례의 환자는 즉각적인 치료로 수술 전 근력에 근접하게 회복될 수 있었다.
두경부 수술에 있어서 경추 척수병증은 드물지만 매우 치명 적인 합병증이다. 장시간 목의 신전이 필요한 두경부 수술을 시행하는 고령 환자는 수술 전 경추 척추증 징후에 대한 상세 한 평가가 이루어져야 한다. 또한 수술 중 목의 자세 변화와 과신전은 최소화되어야 하며 합병증이 발생했을 때는 조기에 감지하여 즉각 신경외과적 중재를 시도하는 것이 중요하다.

\section{ORCID}

Yong Jin Song https://orcid.org/0000-0003-1451-6676

\section{REFERENCES}

1) Young WF. Cervical spondylotic myelopathy: a common cause of spinal cord dysfunction in older persons. Am Fam Physician 2000; 62(5):1064-70.

2) Tracy JA, Bartleson JD. Cervical spondylotic myelopathy. Neurologist 2010;16(3):176-87.

3) Hindman BJ, Palecek JP, Posner KL, Traynelis VC, Lee LA, Sawin $\mathrm{PD}$, et al. Cervical spinal cord, root, and bony spine injuries: a closed claims analysis. Anesthesiology 2011;114(4):782-95.

4) Xiong W, Li F, Guan H. Tetraplegia after thyroidectomy in a patient with cervical spondylosis: a case report and literature review. Medicine (Baltimore) 2015;94(6):e524.

5) Matsumoto M, Fujimura Y, Suzuki N, Nishi Y, Nakamura M, Yabe Y, et al. MRI of cervical intervertebral discs in asymptomatic subjects. J Bone Joint Surg Br 1998;80(1):19-24.

6) Panjabi M, White A 3rd. Biomechanics of nonacute cervical spinal cord trauma. Spine (Phila Pa 1976) 1988;13(7):838-42.

7) Brieg A, Turnbull I, Hassler O. Effects of mechanical stresses on the spinal cord in cervical spondylosis. A study on fresh cadaver material. J Neurosurg 1966;25(1):45-56.

8) Taylor AR. The mechanism of injury to the spinal cord in the neck without damage to the vertebral column. J Bone Joint Surg Br 1951; 33(4):543-7.

9) Muhle C, Weinert D, Falliner A, Wiskirchen J, Metzner J, Baumer M, et al. Dynamic changes of the spinal canal in patients with cervical spondylosis at flexion and extension using magnetic resonance imaging. Invest Radiol 1998;33(8):444-9.

10) Chen WF, Kang CJ, Lee SC, Tsao CK. Quadriplegia secondary to cervical spondylotic myelopathy-a rare complication of head and neck surgery. Head Neck 2013;35(2):E49-E51.

11) Lee SE, Chung CK. Risk prediction for development of traumatic cervical spinal cord injury without spinal instability. Global Spine J 2015;5(4):315-21.

12) Aebli N, Rüegg TB, Wicki AG, Petrou N, Krebs J. Predicting the risk and severity of acute spinal cord injury after a minor trauma to the cervical spine. Spine J 2013;13(6):597-604.

13) RoseBist PK, Peethambaran AK, Peethambar GA. Cervical spondylosis: analysis of clinical and radiological correlation. Int Surg J 2018;5 (2):491-5.

14) Curt A, Dietz V. Ambulatory capacity in spinal cord injury: significance of somatosensory evoked potentials and ASIA protocol in predicting outcome. Arch Phys Med Rehabil 1997;78(1):39-43.

15) Sezer N, Akkuş S, Uğurlu FG. Chronic complications of spinal cord injury. World J Orthop 2015;6(1):24-33.

16) Bracken MB. Methylprednisolone and acute spinal cord injury: an update of the randomized evidence. Spine (Phila Pa 1976) 2001;26(24 Suppl):S47-S54.

17) Fehlings MG, Perrin RG. The timing of surgical intervention in the treatment of spinal cord injury: a systematic review of recent clinical evidence. Spine (Phila Pa 1976) 2006;31(11 Suppl):S28-S35; discussion S36. 